\title{
ANALISIS MEKANISME KOORDINASI DALAM PELAKSANAAN KESELAMATAN PASIEN DI RUMAH SAKIT "X" SURABAYA
}

\author{
Implementation of Coordination Mechanism Analysis in Patient Safety at the Hospital " $X$ " \\ Surabaya
}

\author{
Meutia Ayu Shabrina ${ }^{1}$, Nyoman Anita Damayanti² \\ ${ }^{1}$ Fakultas Kesehatan Masyarakat Universitas Airlangga, meushabrina@gmail.com \\ ${ }^{2}$ Departemen Administrasi dan Kebijakan Kesehatan Fakultas Kesehatan Masyarakat \\ Universitas Airlangga, nyoman.fkmua@gmail.com
}

\begin{abstract}
Management functions should be implemented in order to create a good hospital management, one of which is the coordination function in the hospital. The study was conducted to analyze the coordination mechanism in implementing the hospital patient safety. This was an observational descriptive research with cross-sectional research design. Data was collected by distributing questionnaires to 92 staffs in the Medical Services Unit of the Hospital " $X$ " Surabaya. Subjects were selected by proportional random sampling method. The level of implementation of the safety of patients categorized as good with the percentage of $85,9 \%$. There are seven units which have the reciprocal interdependence type such as Emergency Department, ICU, $2^{\text {nd }}$ Floor Inpatient Unit, $3^{\text {rd }}$ Floor Inpatient Unit, Pharmacy, Radiology, and Laboratory, while Outpatient Unit and Operation Unit have the sequential interdependence type and Nutrition unit have the pooled interdependence type. The coordination mechanism that suits the reciprocal interdependence type is mutual adjustment, while direct supervision suits the sequential interdependence type and standardization suits the pooled interdependence type. This research concludes that the type of interdependence with the greatest number in the Medical Services Unit is reciprocal interdependence, while the appropriate coordination mechanism is the mutual adjustment.
\end{abstract}

Keywords: coordination, interdependence, patient safety 


\begin{abstract}
ABSTRAK
Fungsi manajemen harus dilaksanakan untuk tercipta manajemen rumah sakit yang baik, salah satunya adalah fungsi koordinasi di rumah sakit. Penelitian ini dilakukan untuk menganalisis mekanisme koordinasi dalam pelaksanaan kegiatan terkait keselamatan pasien rumah sakit. Penelitian ini merupakan penelitian deskriptif observasional dengan desain penelitian crosssectional. Pengumpulan data dilakukan dengan menyebarkan kuesioner kepada 92 petugas di unit pelayanan dan penunjang medis Rumah Sakit "X" Surabaya. Subyek penelitian dipilih dengan metode proportional random sampling. Tingkat pelaksanaan keselamatan pasien dikategorikan relatif baik dengan persentase sebesar $85,9 \%$. Ada tujuh unit yang memiliki tipe ketergantungan tugas reciprocal interdependence seperti Instalasi Gawat Darurat, ICU, Unit Rawat Inap lantai 2, Unit Rawat Inap lantai 3, Instalasi Farmasi, Unit Radiologi, dan Unit Laboratorium, sementara Unit Rawat Jalan dan Unit Kamar Operasi memiliki tipe ketergantungan tugas sequential interdependence, dan Unit Gizi memiliki tipe ketergantungan tugas pooled interdependence. Mekanisme koordinasi yang sesuai dengan tipe ketergantungan tugas reciprocal interdependence adalah penyesuaian timbal balik (mutual adjustment), sedangkan pengawasan langsung (direct supervision) sesuai dengan tipe ketergantungan tugas sequential interdependence, dan standarisasi (standardization) sesuai untuk tipe ketergantungan tugas pooled interdependence. Kesimpulan yang dapat ditarik dari penelitian ini yaitu tipe ketergantungan tugas dengan jumlah terbesar pada unit pelayanan dan penunjang medis adalah reciprocal interdependence, dimana mekanisme koordinasi yang sesuai adalah mutual adjustment.
\end{abstract}

\title{
Kata kunci: keselamatan pasien, koordinasi, tipe ketergantungan
}

\section{PENDAHULUAN}

Saat ini ilmu pengetahuan dan teknologi tentang pelayanan kesehatan khususnya di bidang perumahsakitan berkembang pesat. Dengan demikian masalah yang dihadapi oleh rumah sakit semakin kompleks. Ada berbagai macam jenis obat-obatan, teknologi peralatan medis, tenaga profesional medis dan nonmedis, dan berbagai macam pasien dengan jenis penyakitnya di rumah sakit. Apabila keberagaman tersebut tidak diperhatikan dan diatur dengan baik maka akan berpotensi menimbulkan Kejadian Tidak Diinginkan (KTD).

Adanya insiden keselamatan pasien dapat memberikan dampak yang merugikan bagi rumah sakit dan pasien sebagai penerima layanan kesehatan. Dampak yang dapat ditimbulkan dari insiden keselamatan pasien adalah menurunnya kepercayaan masyarakat terhadap rumah sakit sebagai pemberi pelayanan kesehatan dan menurunnya citra rumah sakit, serta menurunnya kualitas atau mutu asuhan yang disediakan oleh rumah sakit karena keselamatan pasien merupakan bagian yang tak terpisahkan dari mutu rumah sakit (Flynn, 2002 dalam Cahyono, 2008).

Rumah Sakit (RS) "X" Surabaya merupakan rumah sakit swasta yang didirikan oleh sebagian besar dokter spesialis yang tergabung dalam Ikatan Ahli Bedah Indonesia (IKABI) bersama rekan swasta yang bergerak di bidang sosial. Program keselamatan pasien di RS " $X$ " Surabaya dikoordinir oleh Tim Keselamatan Pasien Rumah Sakit (KPRS). Selama tahun 2012 - 2014, Tim KPRS masih memiliki permasalahan insiden keselamatan pasien karena terjadi peningkatan yang relatif tinggi yaitu terjadinya fluktuasi angka KTD dan Kejadian Tidak Cedera (KTC). Kejadian Nyaris Cedera (KNC) dan Kejadian Potensi Cedera (KPC) muncul pada tahun 2014 sehingga jumlah kejadian insiden keselamatan pasien berada di angka tertinggi. Meningkatnya KTD tidak selaras dengan sasaran kegiatan program KPRS di RS "X" Surabaya yaitu mereduksi angka KRD sampai dengan 0\%.

Bila dikaji berdasarkan enam sasaran keselamatan pasien, sebagian besar insiden keselamatan pasien di RS " $X$ " 
Surabaya disebabkan oleh faktor identifikasi pasien dan faktor penanganan risiko pasien jatuh yang melibatkan antarunit dalam penyediaan layanan kesehatan. Kedua faktor tersebut merupakan faktor yang berkontribusi terhadap tingginya angka insiden keselamatan pasien pada tahun 2014. Berdasarkan Keputusan Menteri Kesehatan Nomor 129 Tahun 2008 tentang Standar Pelayanan Minimal Rumah Sakit, kejadian pasien jatuh yang menyebabkan kecacatan maupun kematian tidak boleh terjadi di rumah sakit. Namun berdasarkan data laporan insiden keselamatan pasien di RS "X" Surabaya selama tahun 2012-2014 terdapat 3 KTD yang salah satunya menyebabkan kecacatan fisik, $1 \mathrm{KNC}$, dan $1 \mathrm{KPC}$.

Rumah sakit perlu mengupayakan pengelolaan yang mengatur berbagai macam proses yang ada dalam penyediaan pelayanan kesehatan kepada masyarakat. Fungsi manajemen harus diperhatikan agar dapat menciptakan suatu pengelolaan rumah sakit yang baik, salah satunya yaitu fungsi koordinasi antarunit kerja di rumah sakit.

Gittel (2009) berpendapat bahwa koordinasi berperan penting dalam proses pengelolaan pelayanan di rumah sakit baik baik pelayanan medis maupun pelayanan non medis, termasuk koordinasi antarpetugas dan antarunit kerja yang terkait dengan keselamatan pasien rumah sakit. Kegiatan pelayanan kesehatan perlu terkoordinasi dengan baik dan perlu ada tindakan sebagai sebuah kerjasama tim kerja dalam rangka penurunan angka kejadian akibat kesalahan medis (Peters, 2008). Akibat dari pengelolaan kerja dan koordinasi yang buruk dapat dilihat dari rendahnya kepuasan pasien (customer's satisfaction) dan petugas (employee's satisfaction) dan berpotensi menjadi penyebab timbulnya insiden keselamatan pasien.

Penelitian ini bertujuan untuk menganalisis mekanisme koordinasi dalam pelaksanaan keselamatan pasien di Rumah Sakit "X" Surabaya. Penelitian ini diharapkan dapat bermanfaat sebagai bahan evaluasi untuk menentukan kebijakan dan keputusan yang akan datang terkait program keselamatan pasien di Rumah Sakit "X" Surabaya.

Peraturan Menteri Kesehatan Republik Indonesia Nomor 1691 Tahun 2011 tentang Keselamatan Pasien Rumah Sakit menyatakan bahwa keselamatan pasien merupakan suatu sistem di mana rumah sakit membuat asuhan pasien lebih aman yang meliputi asesmen risiko, identifikasi dan pengelolaan hal yang berhubungan dengan risiko pasien, pelaporan dan analisis insiden, kemampuan belajar dari kesalahan dan tindak lanjutnya, serta penerapan solusi untuk menurunkan potensi timbulnya risiko dan mencegah terjadinya cedera yang ditimbulkan karena kelelahan akibat mengambil tindakan atau tidak mengambil tindakan yang seharusnya dilakukan. Ada enam sasaran dalam pelaksanaan keselamatan pasien, yakni ketepatan identifikasi pasien; peningkatan komunikasi yang efektif; peningkatan keamanan obat yang perlu diwaspadai; kepastian tepat-lokasi, tepat-prosedur, tepat-pasien operasi; pengurangan risiko infeksi terkait pelayanan medis; dan pengurangan risiko pasien jatuh.

Keselamatan pasien merupakan disiplin ilmu kesehatan yang mengutamakan keselamatan dalam rangka pencapaian tujuan dari penyediaan layanan kesehatan. Emanuel, dkk. (2008) menyatakan bahwa keselamatan pasien merupakan suatu atribut sistem pengelolaan perawatan kesehatan yang bertujuan untuk memaksimalkan proses penyembuhan pasien dan meminimalisasi risiko dan dampak dari KTD di fasilitas pelayanan kesehatan.

Mintzberg (1983) menyatakan bahwa koordinasi merupakan upaya pelaksanaan proses bersama dengan baik sesuai dengan keputusan bersama yang telah disusun sebelumnya. Tujuan diadakannya koordinasi adalah untuk menyelaraskan semua kegiatan antarunit kerja, instansi, atau pejabat ke arah pencapaian bersama secara keseluruhan (Wijono, 2009). 
Menurut Mintzberg (1983), ada 3 (tiga) macam mekanisme koordinasi yang perlu diperhatikan sebagai prinsip dasar sebuah struktur dalam suatu organisasi, diantaranya Mutual Adjustment (Penyesuaian Timbal Balik), yaitu mekanisme koordinasi yang mengutamakan komunikasi informal antarpetugas dalam melaksanakan tugas. Kesepahaman diperlukan oleh antarpetugas dalam melaksanakan koordinasi jenis ini agar dapat mengerjakan tugas secara optimal; Direct Supervision (Supervisi Secara Langsung), yaitu mekanisme koordinasi yang melibatkan seseorang sebagai penanggung jawab atas pekerjaan yang dilakukan oleh petugas sehingga dapat mempermudah pengawasan; dan Standardization (Standarisasi), yaitu mekanisme koordinasi dengan menyusun protap, aturan, atau tata cara kerja yang bertujuan untuk meningkatkan dan menyetarakan kemampuan petugas serta menyelaraskan tujuan yang akan dicapai bersama.

Organisasi tersusun atas unit-unit yang saling berhubungan, di mana setiap unit yang saling berhubungan itu memberikan kontribusi dalam bentuk yang berbeda. Menurut Handoko (2003) berdasarkan teori dari James D. Thompson, tipe ketergantungan tugas terdiri atas 3 jenis, yaitu Reciprocal Interdependence (Ketergantungan Timbal Balik) yang merupakan tipe ketergantungan tugas yang menghubungkan antarunit dalam memberi hasil kerja (output) dan menerima masukan (input) antarunit dalam suatu organisasi untuk mencapai tujuan yang akan dicapai bersama; Sequential Interdependence (Ketergantungan Berurutan) yang merupakan tipe ketergantungan tugas yang saling berurutan di mana suatu unit dalam organisasi harus menyelesaikan tugasnya terlebih dahulu sebelum unit lain dapat bekerja; dan Pooled Interdependence (Ketergantungan Terpusat / Berkelompok) yang merupakan tipe ketergantungan tugas yang saling menyatu dan tidak memerlukan adanya interaksi antarunit secara intens karena tugas masing-masing unit dapat dilakukan secara terpisah. Masing - masing tipe ketergantungan tugas menentukan mekanisme koordinasi yang sesuai. Tabel 1 dapat menggambarkan tipe ketergantungan tugas dan mekanisme koordinasi yang sesuai.

Tabel 1. Tipe Ketergantungan dan Mekanisme Koordinasi yang Sesuai

\begin{tabular}{ll}
\hline \multicolumn{1}{c}{ Tipe } & \multicolumn{1}{c}{$\begin{array}{c}\text { Mekanisme } \\
\text { Koordinasi }\end{array}$} \\
\hline Reciprocal & Mutual \\
Interdependence & Adjustment \\
Sequential & Direct \\
Interdependence & Supervision \\
Pooled & Standardization \\
Interdependence & \\
\hline
\end{tabular}

\section{METODE PENELITIAN}

Penelitian ini termasuk penelitian observasional deskriptif karena tidak memberikan intervensi apapun pada subyek penelitian dan bertujuan untuk mendeskripsikan pelaksanaan keselamatan pasien dan mekanisme koordinasi yang sesuai untuk masing-masing unit kerja terkait tugas dalam pelaksanaan keselamatan pasien. Rancang bangun penelitian ini adalah cross sectional yaitu data yang dikumpulkan pada suatu waktu tertentu untuk menggambarkan keadaan dan kegiatan pada waktu tersebut.

Penelitian ini dilaksanakan di unit kerja pelayanan medis yang terdapat di dalam RS " $X$ " Surabaya. Penelitian ini dilakukan mulai bulan November 2015 sampai dengan bulan Juli 2016. Populasi dalam penelitian ini adalah seluruh instalasi dan unit kerja pelayanan medis di RS " $X$ " Surabaya yaitu Instalasi Gawat Darurat, Unit Kamar Operasi, Intensive Care Unit, Unit Laboratorium, Unit Gizi, Unit Radiologi, Unit Farmasi, Unit Rawat Inap lantai 2, Unit Rawat Inap lantai 3, dan Unit Rawat Jalan dan Rehabilitasi Medik populasi sejumlah 120 orang. Pengambilan sampel dilakukan dengan metode proportional random sampling yaitu pengambilan sampel dengan memproporsikan sampel berdasarkan jumlah populasi per unit kerja sehingga diharapkan keseluruhan sampel dapat mewakili setiap unit kerja yang ada. Besar sampel yang terhitung untuk penelitian ini 
dihitung berdasarkan rumus sampel minimal untuk satu populasi sehingga menghasilkan sejumlah 92 orang.

Tahapan yang dilakukan pada penelitian ini yaitu mengidentifikasi pelaksanaan keselamatan pasien di unit-unit kerja pelayanan medis RS " $X$ " Surabaya, kemudian dilakukan identifikasi tipe ketergantungan pada tugas pokok masingmasing unit kerja terkait pelaksanaan keselamatan pasien, dan tahap terakhir adalah menarik kesimpulan mengenai mekanisme koordinasi yang sesuai dengan tipe ketergantungan prioritas pada masingmasing unit kerja pelayanan medis di RS "X" Surabaya.

Jenis data yang dikumpulkan pada penelitian ini adalah data primer. Data dikumpulkan dengan menggunakan instrumen kuesioner kepada 92 petugas dengan jumlah pertanyaan sebanyak 26 pertanyaan. Muatan dalam kuesioner yang digunakan dalam penelitian ini meliputi penilaian petugas terhadap pelaksanaan keselamatan pasien dan proses koordinasi. Kuesioner untuk pengumpulan data telah diuji validitas dan reliabilitas terlebih dahulu sebelum dibagikan kepada responden.

Teknik analisis data pada variabel pelaksanaan keselamatan pasien dinilai dari pelaksanaan kegiatan dalam mencapai enam sasaran keselamatan pasien (ketepatan identifikasi pasien, peningkatan komunikasi yang efektif, peningkatan keamanan obat yang perlu diwaspadai, kepastian tepat-lokasi, tepat-prosedur, dan tepat-pasien operasi, pengurangan risiko infeksi terkait pelayanan kesehatan, dan pengurangan risiko pasien jatuh) dan pelaporan insiden keselamatan pasien. Variabel pelaksanaan keselamatan pasien diukur melalui 8 pertanyaan berdasarkan unsur yang mendukung pelaksanaan keselamatan pasien kemudian dihitung nilai rata-rata untuk setiap responden. Setiap jawaban memiliki interval nilai: benar $=1$ dan salah $=0$. Variabel pelaksanaan keselamatan pasien dikelompokkan dalam kategori: baik (nilai 6-8), sedang (nilai 35), dan kurang (nilai $0-2$ ). Variabel tipe ketergantungan dianalisis melalui pertanyaan terkait tugas pokok dari masing - masing unit kerja terkait pelaksanaan keselamatan pasien dan hubungan koordinasi antarunit kerja terkait masingmasing tugas pokok dalam pelaksanaan program KPRS. Hasil pengukuran dikategorikan ke dalam 3 (tiga) kategori tipe ketergantungan tugas, yaitu reciprocal interdependence jika tugas pokok dikerjakan bersama dengan unit lain, sequential interdependence jika input atau output dari tugas pokok membutuhkan atau dibutuhkan unit kerja lain, dan pooled interdependence jika jenis tugas pokok dapat dikerjakan oleh unit kerja tersebut tanpa kerjasama dengan unit kerja lain. Tipe ketergantungan tugas prioritas yang teridentifikasi pada masing - masing unit kerja mempengaruhi mekanisme koordinasi yang sesuai dengan unit kerja tersebut. Mekanisme koordinasi dikategorikan menjadi 3 (tiga) jenis meliputi mutual adjustment (penyesuaian timbal balik) untuk tipe ketergantungan tugas reciprocal interdependence, direct supervision (supervisi secara langsung) untuk tipe ketergantungan tugas sequential interdependence, dan standardization (standarisasi) untuk tipe ketergantungan tugas pooled interdependence (Bijman, 2003).

\section{HASIL PENELITIAN DAN PEMBAHASAN}

\section{Gambaran Pelaksanaan Keselamatan Pasien}

Sebagian besar petugas melaksanakan kegiatan keselamatan pasien dengan kategori baik, meskipun masih terdapat beberapa petugas yang berada pada kategori cukup. Hal ini menunjukkan bahwa secara umum petugas telah melaksanakan kegiatan keselamatan pasien dengan benar. Tingkat pelaksanaan keselamatan pasien oleh petugas yang teridentifikasi dari hasil analisis pengolahan data dari kuesioner dijabarkan dalam Tabel 2 berikut. 
Tabel 2. Tingkat Pelaksanaan Keselamatan Pasien di RS " $X$ " Surabaya Tahun 2016

\begin{tabular}{lcc}
\hline \multicolumn{1}{c}{ Kategori } & N & \% \\
\hline Baik & 79 & 85,9 \\
Sedang & 13 & 14,1 \\
Kurang & 0 & 0,0 \\
Total & $\mathbf{9 2}$ & $\mathbf{1 0 0 , 0}$ \\
\hline
\end{tabular}

Sebagian besar petugas melaksanakan kegiatan keselamatan pasien dengan kategori baik, yaitu sebanyak 85,9\% dari total seluruh petugas. Salah satu faktor yang dapat menyebabkan tingginya tingkat pelaksanaan keselamatan pasien yaitu adanya program pendidikan dan pelatihan yang telah diselenggarakan oleh Tim KPRS pada bulan April 2016. Cahyono (2008) menyatakan bahwa pelatihan merupakan suatu proses sistematik dan terorganisasi yang bertujuan untuk memberi pengaruh terhadap produktivitas, kinerja, dan pekerjaan petugas secara efektif serta mampu menguasai suatu hal khusus yang menjadi tanggung jawab dari pekerjaan yang dilakukan oleh petugas. Hasil yang diharapkan dari suatu pelatihan yaitu proses pengambilan keputusan yang lebih baik dalam bertindak sehingga petugas akan meminimalisasi potensi melakukan kesalahan. Peningkatan pengetahuan perlu dilakukan oleh petugas dengan mempelajari referensi terkait peningkatan budaya keselamatan pasien (Fleming, 2005).

Aspek pelaksanaan keselamatan pasien dapat ditelaah lebih rinci dengan mengevaluasi tingkat ketepatak responden dalam menjawab setiap pertanyaan tentang pelaksanaan keselamatan pasien seperti ditunjukkan dalam Tabel 3 berikut.

Tabel 3. Tingkat Ketepatan dalam Menjawab Pertanyaan Terkait Pelaksanaan Keselamatan Pasien di RS "X" Surabaya Tahun 2016

\begin{tabular}{|c|c|c|c|}
\hline \multirow{2}{*}{ No. } & \multirow{2}{*}{ Muatan Pertanyaan } & \multicolumn{2}{|c|}{ Tingkat Ketepatan } \\
\hline & & $\mathbf{N}$ & $\%$ \\
\hline & $\begin{array}{l}\text { Mengidentifikasi pasien menggunakan dua identitas } \\
\text { pasien (nama dan tanggal lahir }\end{array}$ & 88 & 95,7 \\
\hline & $\begin{array}{l}\text { Waktu pelaksanaan identifikasi pasien (sebelum } \\
\text { pemberian obat, darah, atau produk darah) }\end{array}$ & 61 & 66,3 \\
\hline 3. & $\begin{array}{l}\text { Mengetahui adanya kebijakan / prosedur terkait } \\
\text { identifikasi pasien }\end{array}$ & 91 & 98,9 \\
\hline & $\begin{array}{l}\text { Peningkatan komunikasi efektif dengan metode read } \\
\text { back }\end{array}$ & 85 & 92,4 \\
\hline 5. & Peningkatan kewaspadaan terhadap elektrolit konsentrat & 71 & 77,2 \\
\hline & $\begin{array}{l}\text { Kepastian tepat lokasi operasi pasien dengan melibatkan } \\
\text { pasien saat proses penandaan }\end{array}$ & 74 & 80,4 \\
\hline 7. & Perlunya pencegahan infeksi oleh pengunjung pasien & 77 & 83,7 \\
\hline & $\begin{array}{l}\text { Pelaporan insiden keselamatan pasien kurang dari } 2 \text { x } 24 \\
\text { jam setelah kejadian }\end{array}$ & 84 & 91,3 \\
\hline
\end{tabular}

Tingkat ketepatan dalam menjawab oleh petugas menunjukkan angka tertinggi dengan persentase sebesar $98,9 \%$ pada pertanyaan terkait pengetahuan mengenai adanya kebijakan / prosedur identifikasi pasien, sedangkan tingkat ketepatan dalam menjawab oleh petugas menunjukkan angka terendah dengan persentase sebesar $66,3 \%$ terletak pada pertanyaan tentang pemahaman terkait waktu dilaksanakannya identifikasi pasien. Beberapa petugas belum memahami bahwa pelaksanaan identifikasi pasien seharusnya dilakukan sebelum pemberian obat, darah, atau produk darah seperti yang tertuang dalam Peraturan Menteri Kesehatan Nomor 1691 Tahun 2011 tentang Keselamatan Pasien Rumah Sakit sehingga dapat dikatakan bahwa petugas telah mengetahui adanya kebijakan / prosedur yang mengatur pelaksanaan identifikasi pasien, namun dalam pelaksanaannya masih terdapat beberapa petugas yang melaksanakan identifikasi pasien pada waktu yang tidak tepat.

Pelaksanaan koordinasi di unit pelayanan medis RS " $X$ " Surabaya ditentukan dari tipe ketergantungan tugas antarunit kerja sehingga dapat menentukan 
mekanisme koordinasi yang sesuai. Tipe ketergantungan ditentukan berdasarkan hubungan kerja antarunit dalam melaksanakan tugas pokok terkait KPRS. Untuk menentukan tipe ketergantungan tugas prioritas, unit kerja yang memiliki lebih dari satu tipe ketergantungan tugas akan ditentukan berdasarkan jumlah ketergantungan tugas terbanyak dengan unit lain dan urutan prioritas tipe ketergantungan tugas yakni reciprocal interdependence, interdependence, sequential dan pooled interdependence. Tipe ketergantungan tugas antarunit kerja dalam melaksanakan tugas terkait KPRS di RS " $X$ " Surabaya dapat diidentifikasi seperti pada Tabel 4 berikut.

Tabel 4. Tipe Ketergantungan Tugas Antarunit Kerja Terkait Pelaksanaan Keselamatan Pasien di RS "X" Surabaya Tahun 2016

\begin{tabular}{|c|c|c|c|c|}
\hline \multirow[b]{2}{*}{ No. } & \multirow[b]{2}{*}{ Unit Kerja } & \multicolumn{3}{|c|}{ Tipe Ketergantungan Tugas } \\
\hline & & $\begin{array}{c}\text { Reciprocal } \\
\text { Interdependence }\end{array}$ & $\begin{array}{c}\text { Sequential } \\
\text { Interdependence }\end{array}$ & $\begin{array}{c}\text { Pooled } \\
\text { Interdependence }\end{array}$ \\
\hline 1. & Instalasi Gawat Darurat & Far, Rad, Lab (3) & $\begin{array}{c}\text { Ranap 2, Ranap 3, } \\
\text { ICU (3) }\end{array}$ & $\begin{array}{l}\text { Rajal, OK, Gizi } \\
\text { (3) }\end{array}$ \\
\hline 2. & Intensive Care Unit & $\begin{array}{c}\text { Lab, Gizi, Rad, Far } \\
\text { (4) }\end{array}$ & $\begin{array}{c}\text { IGD, Ranap 2, Ranap } \\
\text { 3, OK (4) }\end{array}$ & Rajal (1) \\
\hline 3. & $\begin{array}{l}\text { Unit Rawat Jalan dan } \\
\text { Rehabilitasi Medik }\end{array}$ & Lab, Rad, Far (3) & $\begin{array}{l}\text { OK, Gizi, Ranap 2, } \\
\text { Ranap } 3 \text { (4) }\end{array}$ & IGD, ICU (2) \\
\hline 4. & Unit Rawat Inap lantai 2 & $\begin{array}{l}\text { Lab, OK, Rad, Far } \\
\text { (4) }\end{array}$ & $\begin{array}{c}\text { ICU, Rajal, IGD, Gizi } \\
\text { (4) }\end{array}$ & Ranap 3 (1) \\
\hline 5. & Unit Rawat Inap lantai 3 & $\begin{array}{c}\text { Lab, OK, Rad, Far } \\
\text { (4) }\end{array}$ & $\begin{array}{c}\text { ICU, Rajal, IGD, Gizi } \\
\text { (4) }\end{array}$ & Ranap 2 (1) \\
\hline 6. & Instalasi Farmasi & $\begin{array}{c}\text { ICU, Rajal, Ranap } \\
\text { 2, Ranap 3, IGD, } \\
\text { OK (6) }\end{array}$ & $-(0)$ & Lab, Gizi, Rad (3) \\
\hline 7. & Unit Radiologi & $\begin{array}{l}\text { ICU, Rajal, Ranap } \\
\text { 2, Ranap 3, IGD } \\
\text { (5) }\end{array}$ & OK (1) & Lab, Gizi, Far (3) \\
\hline 8. & $\begin{array}{l}\text { Unit Gizi Klinik dan Food } \\
\text { and Beverage }\end{array}$ & $\operatorname{ICU}(1)$ & $\begin{array}{l}\text { Rajal, Ranap 2, } \\
\text { Ranap } 3 \text { (3) }\end{array}$ & $\begin{array}{l}\text { Lab, OK, IGD, } \\
\text { Rad, Far (5) }\end{array}$ \\
\hline 9. & Unit Kamar Operasi & $\begin{array}{c}\text { Ranap 2, Ranap 3, } \\
\text { Far (3) }\end{array}$ & $\begin{array}{c}\text { Rad, Lab, ICU, Rajal } \\
\text { (4) }\end{array}$ & IGD, Gizi (2) \\
\hline 10. & Unit Laboratorium & $\begin{array}{l}\text { IGD, ICU, Rajal, } \\
\text { Ranap 2, Ranap } 3\end{array}$ & $\mathrm{OK}(1)$ & Gizi, Rad, Far (3) \\
\hline
\end{tabular}

Keterangan : IGD (Instalasi Gawat Darurat), ICU (Intensive Care Unit), Rajal (Unit Rawat Jalan dan Rehabilitasi Medik), Ranap 2 (Unit Rawat Inap lantai 2), Ranap 3 (Unit Rawat Inap lantai 3), Far (Instalasi Farmasi), Rad (Unit Radiologi), Gizi (Unit Gizi Klinik dan Food and Beverage), OK (Unit Kamar Operasi), dan Lab (Unit Laboratorium).

Instalasi Gawat Darurat, Intensive Care Unit, Unit Rawat Inap lantai 2, Unit Rawat Inap lantai 3, Instalasi Farmasi, Unit Radiologi, dan Unit Laboratorium memiliki tipe ketergantungan tugas prioritas yaitu reciprocal interdependence. Tugas pokok yang menjadi dasar pertimbangan penggolongan tipe ketergantungan tugas tersebut adalah adanya timbang terima pasien antarunit kerja sehingga memerlukan frekuensi koordinasi yang relatif sering karena tugas pokok antarunit kerja tersebut saling menunggu dan ditunggu oleh unit kerja lain. Hasil kerja satu unit kerja menjadi input bagi tugas unit kerja lain, begitu pula sebaliknya (Gittel, 2009).

Unit Rawat Jalan dan Rehabilitasi Medik dan Unit Kamar Operasi memiliki tipe ketergantungan tugas prioritas sequential interdependence. Tipe ketergantungan tugas ini saling berurutan di mana suatu bagian dalam organisasi menunggu hasil dari bagian lain untuk dapat menyelesaikan tugasnya atau bagian 
tersebut harus menyelesaikan tugasnya terlebih dahulu sebelum bagian lain dapat bekerja. Beberapa tugas diselesaikan secara berurutan karena output dari suatu unit menjadi input bagi unit lain (Ivancevich, et al., 2011). Penyusunan jadwal kerja dapat diupayakan bagi unit kerja dengan tipe ketergantungan tugas sequential interdependence untuk mempertahankan keberlangsungan kerja dan tidak saling menghambat tugas antarunit kerja.

$$
\text { Unit kerja dengan tipe }
$$

ketergantungan tugas pooled

interdependence adalah Unit Gizi Klinik dan Food and Beverage. Ciri - ciri tugas pokok Unit Gizi Klinik dan Food and Beverage dapat dikerjakan tanpa melibatkan unit kerja lain, misalnya menghitung waste food pasien, menyiapkan makanan pasien, dan memisahkan alat makan antara pasien biasa dengan pasien infeksius. Tipe ketergantungan tugas pooled interdependence tidak membutuhkan interaksi dengan unit kerja lain karena tugas unit dilaksanakan secara terpisah (Bijman, 2003). Meski cara kerja unit dengan tipe ketergantungan tugas pooled interdependence secara terpisah, kinerja setiap unit menjadi penentu kesuksesan organisasi.

Mekanisme koordinasi terkait tugas KPRS antarunit kerja di RS "X" Surabaya ditentukan berdasarkan tipe ketergantungan tugas prioritas unit kerja. Mekanisme koordinasi mutual adjustment berlaku untuk tipe ketergantungan tugas reciprocal interdependence, direct supervision untuk tipe ketergantungan tugas sequential interdependence, dan standardization untuk tipe ketergantungan tugas pooled interdependence (Bijman, 2003). Mekanisme koordinasi yang disarankan sebagai dasar optimalisasi proses koordinasi antarunit kerja terkait program KPRS di RS "X” Surabaya dapat dipelajari pada Tabel 5 berikut.

Tabel 5. Mekanisme Koordinasi yang Disarankan sesuai dengan Tipe Ketergantungan Tugas Prioritas Unit Kerja Terkait Program KPRS di RS "X" Surabaya Tahun 2016

\begin{tabular}{rlll}
\hline No. & \multicolumn{1}{c}{ Unit Kerja } & \multicolumn{1}{c}{$\begin{array}{c}\text { Tipe Ketergantungan } \\
\text { Tugas Prioritas }\end{array}$} & Mekanisme Koordinasi \\
\hline 1. & Instalasi Gawat Darurat & Reciprocal interdependence & Mutual adjustment \\
2. & Intensive Care Unit & Reciprocal interdependence & Mutual adjustment \\
3. & Unit Rawat Jalan dan Rehabilitasi & Sequential interdependence & Direct supervision \\
& Medik & & \\
4. & Unit Rawat Inap lantai 2 & Reciprocal interdependence & Mutual adjustment \\
5. & Unit Rawat Inap lantai 3 & Reciprocal interdependence & Mutual adjustment \\
6. & Instalasi Farmasi & Reciprocal interdependence & Mutual adjustment \\
7. & Unit Radiologi & Reciprocal interdependence & Mutual adjustment \\
8. & Unit Gizi Klinik dan Food and & Pooled interdependence & Standardization \\
& Beverage & & \\
9. & Unit Kamar Operasi & Sequential interdependence & Direct supervision \\
10. & Unit Laboratorium & Reciprocal interdependence & Mutual adjustment \\
\hline
\end{tabular}

Salah satu bentuk pelaksanaan mekanisme koordinasi mutual adjustment adalah dengan komunikasi infiormal antarunit kerja ddengan frekuensi tinggi. Keberhasilan mekanisme koordinasi mutual adjustment bergantung pada kemampuan petugas untuk saling beradaptasi sehingga mekanisme koordinasi ini membutuhkan hubungan yang baik antarpetugas. Mekanisme koordinasi mutual adjustment perlu diterapkan oleh Instalasi Gawat Darurat, Intensive Care Unit, Unit Rawat Inap lantai 2, Unit Rawat Inap lantai 3,
Instalasi Farmasi, Unit Radiologi, dan Unit Laboratorium.

Unit kerja yang perlu menerapkan mekanisme koordinasi direct supervision yaitu Unit Rawat Jalan dan Rehabilitasi Medik dan Unit Kamar Operasi. Mekanisme koordinasi direct supervision dilakukan dalam bentuk keterlibatan seseorang yang bertugas sebagai koordinator untuk mengawasi, meninjau, dan bertanggung jawab dalam proses pengerjaan tugas (Lunenburg, 2012). Apabila tidak terdapat pengawasan dan 
penjadwalan yang baik, maka aktivitas unit lain dapat terganggu.

Unit Gizi Klinik dan Food and Beverage memiliki mekanisme koordinasi standardization, yaitu mekanisme koordinasi yang dapat dilakukan dengan penyusunan prosedur tetap (protap) atau Standar Prosedur Operasional (SPO) dari tugas pokok terkait program KPRS. Selain itu, standardization dapat berupa spesifikasi jabatan untuk perekrutan petugas, pendidikan dan pelatihan untuk menyetarakan kemampuan, dan perencanaan sasaran yang akan dicapai bersama sehingga petugas dapat mengetahui apa saja yang perlu dilakukan masing-masing tanpa memperhatikan kinerja unit lain (Mintzberg, 1983).

\section{SIMPULAN DAN SARAN}

Sebagian besar petugas melaksanakan kegiatan keselamatan pasien dengan kategori relatif baik. Tingkat ketepatan dalam menjawab pertanyaan terkait pelaksanaan keselamatan pasien dengan persentase paling sedikit terletak pada pertanyaan terkait waktu pelaksanaan identifikasi pasien.

Tipe ketergantungan tugas unit kerja terkait keselamatan pasien terbagi menjadi 3 (tiga) kategori, yaitu: reciprocal interdependence,

interdependence, dan pooled interdependence. Tipe ketergantungan tugas yang paling banyak teridentifikasi di unit kerja pelayanan medis RS " $\mathrm{X}$ " Surabaya adalah reciprocal interdependence sehingga mekanisme koordinasi yang sesuai untuk reciprocal interdependence adalah mutual adjustment, yaitu mekanisme dengan tingkat koordinasi terkait tugas antarunit kerja dengan intensitas tinggi.

Beberapa saran yang diusulkan untuk memperbaiki permasalahan tersebut yaitu dengan melaksanakan sosialisasi tentang KPRS dengan kemasan lebih menarik (misal: menggunakan media audiovisual, membuat cerita singkat, dan lain sebagainya) sehingga petugas dapat lebih memahami pelaksanaan keselamatan pasien dengan benar. Selain itu, solusi lain yang dapat dilakukan adalah dengan pembuatan penilaian kinerja karyawan dengan sistem reward bagi unit yang paling sedikit mengalami insiden keselamatan pasien. Optimalisasi fungsi koordinasi dapat dilakukan dengan penyusunan SPO terkait tugas dan wewenang pada masingmasing unit kerja dengan mencantumkan perlunya koordinasi dengan unit lain terkait tugas sehingga ketergantungan tugas dapat dipahami dengan baik, serta meningkatkan koordinasi dengan komunikasi informal dalam berbagai macam bentuk seperti kegiatan olah raga bersama, arisan, pengajian rutin, dan pertemuan lainnya untuk mengelola kepadatan tugas yang berbeda pada masing-masing unit. Tim KPRS sebaiknya mengagendakan pertemuan rutin yang dihadiri oleh seluruh unit kerja terkait pelayanan medis untuk menyusun perencanaan, menyelesaikan permasalahan, dan mencari solusi dalam kegiatan - kegiatan yang mendukung praktik keselamatan pasien.

\section{DAFTAR PUSTAKA}

Bijman, J., 2003. Multiple Interdependencies: Applying The Netchain Approach to Cooperative Restructurin. Jerman: Conference of Vertical Markets and Cooperative Hierarchies.

Cahyono, J.S.B. (2008). Membangun Budaya Keselamatan Pasien dalam Praktik Kedokteran. Yogyakarta: Kanisisus.

Emanuel, L. et al. (2008). What Exactly Is Patient Safety? Advances in Patient Safety: New Directions and Alternative Approaches, 1 (18), 6.

Fleming, M. (2005). Patient Safety Culture Measurement and Improvement: A "How To" Guide. Health Care Quarterly, 8 (Special), 14-19.

Gittel, J.H. (2009). High Performance Healthcare: Using The Power of Relationships to Achieve Quality, Efficiency, and Resilience. New York: McGraw-Hill. 
Handoko, T.H. (2003). Manajemen. Edisi Kedua. Yogyakarta: BPFE.

Ivancevich, J. M., Konopaske, R. \& Matteson, M.T. (2011). Organizational Behavior and Management. $9^{\text {th }}$ ed. New York: McGraw-Hill Higher Education.

Lunenburg, F. C., 2012. Organizational Structure: Mintzberg's Framework. International Journal of Scholarly, Academic, Intellectual Diversity, 14 (1).

Mintzberg, H. (1983). Structure in Fives: Designing Effective Organizations. New Jersey: Prentice-Hall.

Keputusan Menteri Kesehatan Republik Indonesia Nomor 129 Tahun 2008 tentang Standar Pelayanan Minimal Rumah Sakit.

Peraturan Menteri Kesehatan Republik Indonesia Nomor 1691 Tahun 2011 tentang Keselamatan Pasien Rumah Sakit.

Peters, G.A. (2008). Medical Error and Patient Safety: Human Factors in Medicine. New York: CRC Press.

Wijono, D., 2009. Manajemen Program dan Kepemimpinan Kesehatan. Surabaya: CV. Duta Prima Airlangga. 